\title{
DEL SUR AL NORTE. \\ EL TRAYECTO EUROPEO DEL ANTILLANISMO CANÍBAL
}

\author{
Erla Erlendsdóttir \\ Universidad de Islandia
}

\section{Resumen}

En este artículo se estudia la presencia en las lenguas danesa e islandesa de la voz caníbal. Se trata de una palabra de origen antillano que ha penetrado en las lenguas europeas a través del español a partir del siglo xvi. Se pretende trazar el camino seguido por el vocablo seleccionado desde España - lengua vehicular de la mayoría de las voces amerindias prehispanas - hasta las lenguas receptoras: italiano, alemán, danés e islandés. Además de señalar la fecha y fuente de la primera documentación de la voz objeto de este estudio se examinarán los cambios formales y semánticos que ha sufrido.

Palabras clave: Caníbal, préstamo, lenguas europeas, danés, islandés.

\section{FROM SOUTH TO NORTH. THE ITINERARY OF THE ANTILLES LOANWORD CANÍBAL IN EUROPE}

\begin{abstract}
This article deals with the presence of the Antilles loanword caníbal in Danish and Icelandic. It appears to be a loanword of a Caribbean origin which was borrowed via Spanish by other European languages from the 16th century onwards. The history of the word is explained from Spanish - vehicular language of most of the pre-Hispanic Amerindian voices - to the recipient languages: Italian, German, Danish and Icelandic. The first written sources of the word are documented and the formal and semantic changes undergone by it are also examined.

Keywords: Cannibal, loanword, European languages, Danish, Icelandic.
\end{abstract}




\section{Introducción}

Tras la llegada a América en 1492, los españoles relataban a su regreso las andanzas por tierras para ellos antes desconocidas. Dejaron asimismo testimonios escritos del encuentro con este nuevo mundo. Se trata de textos que dan cuenta de lo visto y lo vivido por los viajeros, textos que contribuyeron a la configuración y la difusión de una imagen de América y sus habitantes en Europa.

Desde Españalas noticias sobre eldescubrimiento de un nuevo mundo se divulgaron a otros países europeos, generalmente en letra impresa. La labor de traductores, copistas e impresores tuvo por efecto que pronto aparecieran y circularan traducciones de cartas escritas por Colón y Cortés, o traslaciones de textos de Oviedo y Gómara, así como de relatos y narraciones de tema americano en ciudades como Roma, Venecia, Basilea, Augsburgo, Núremberg, Fráncfort, París y Amberes. Del periodo que media entre finales del siglo xvy mediados del siglo xvi se conoce la existencia de 515 textos sobre el Nuevo Mundo. De estos, 260 están escritos en latín y 255 en la lengua del país donde se publicaron. Alrededor del $35 \%$ de los textos aparece en el ámbito de la lengua alemana, en Holanda y en Inglaterra; y de estos, el 35,3\% se publicó en las respectivas lenguas vernáculas (Sixel, 1966: 47-48).

Los textos sobre el Nuevo Mundo llegaron también a Dinamarca, aunque con un retraso de 150 años, como ha indicado Horstbøll (1999: 507); en el siglo xvii se imprimen traducciones danesas relacionadas con este tema (Horstbøll, 1999: 507). A través de Copenhague llegaron a Islandia textos daneses de tema americano que pronto fueron traducidos a la lengua islandesa. En efecto, en la sección de manuscritos de la Biblioteca Nacional de Islandia se encuentran manuscritos de los siglos xvii, xviii y xix que contienen relatos sobre Colón y Cortés, Vespucio y Pizarro.

Las traducciones de textos de tema americano indican, por un lado, el camino que siguieron, desde España y hasta el norte, las noticias sobre tierras recién encontradas y sus habitantes y, por el otro, nos dan una idea sobre la posible ruta de las voces que proceden de las distintas lenguas indígenas incorporadas a las lenguas europeas.

En este artículo pretendemos seguir el posible camino, desde el sur hasta el norte, de un texto escrito en España hacia finales del siglo xv en el que se encuentra la voz antillana caníbal.

\section{Caníbal-Caribe}

Como queda dicho, en los relatos de Colón, Vespucio y otros expedicionarios, aparecen descripciones de los nativos de las Antillas, sobre todo de 
los supuestos antropófagos del Caribe. Las noticias que resultaron ser de mayor interés para los europeos en aquella época fueron efectivamente las referidas a esa gente, así como otros elementos relacionados a la vida y las costumbres de los nativos en general. En las noticias y los textos sobre los pobladores aparece el gentilicio caribe o caníbal, una denominación que junto con la noticia pasa de un texto a otro, de una traducción a otra y, consecuentemente, de una lengua a otra.

Según Buesa Oliver y Enguita Utrilla (1992: 66), caníbal y caribe se remontan a un étimo común: canib o carib, gentilicio de origen caribe. Se trata de una voz cuya primera documentación se recoge en el Diario de a bordo del primer viaje al Nuevo Mundo. El día 23 de noviembre de 1492, Colón anota que en una tierra había "gente que tenía un ojo en la frente, y otros que se llamavan caníbales" a quienes tenían gran miedo los indígenas que llevaba a bordo y decían que "los comían" y que era "gente muy armada" (Colón, 1996: 103).

El 26 de noviembre vuelve a mencionar los Caniba o Canima de los que tanto miedo tenían los taínos: "[...] temiendo que los avian de comer, y no les podía quitar el temor, y dezian que no tenían sino un ojo y la cara de perro [...]" (Colón, 1996: 124). Y otra vez, el 11 de diciembre, Colón vuelve a hablar de los Caritaba o Caniba y anota que "no es otra cosa sino la gente del Gran Can [...]" (Colón, 1996: 124). De hecho, Colón creía que se encontraba cerca de su destino: la China. Y de ahí surge posiblemente este cambio de caribe a caniba, con alusión a la gente del Gran Can, apunta Trumbull (1875: 171-171; oed 1989: 837). E1 26 de diciembre escribe caribe: "[...] le pareció gran cosa, aunque diz que el comienço fue sobre él habla de los Caniba, qu'ellos llaman caribes [...]" (Colón, 1996: 153). Por lo citado queda claro que en el diario de Colón aparecen varios significantes para referirse a los pobladores de la zona antillana que supuestamente comían carne humana.

Las últimas décadas han surgido varias hipótesis para explicar el cambio formal de la palabra en cuestión. König y Lenz opinan que caníba(l) con el significado de 'antropófago' surge quizás por asociación con el latín canis, el italiano cane y el español can, 'perro' (König, 1939: 49; Lenz, 1904: 181; Henriquez Ureña, 1938: 96-97). Una hipótesis que Trumbull (1875: 171-172; oed, 1989: 8) rechaza como una delusión ${ }^{1}$. Otros lingüistas comentan que puede tratarse de variantes en la pronunciación de los diversos dialectos hablados en la zona antillana en aquella época y de ahí que en los distintos

${ }^{1}$ Etimología probablemente inventada por Geraldini, obispo de Santo Domingo en 15211525 (Trumbull, 1875: 171-172). 
textos aparezcan formas como carib, caniba y galibi. En este sentido debe recordarse que la palabra la escuchó Colón en boca de los indios de distintas islas del Caribe (Friederici, 1960: 143). Por otro lado hay lingüistas que han indicado que los isleños no distinguían entre los fonemas $/ \mathrm{r} / \mathrm{y} / 1 /$. Taylor (1958: 156) dice en cuanto a esto que:

[...] these differences are not very important, for no Cariban language has, so far as I know, an 1/r-opposition or more than one series of stops; and while this is not true of all Arawakan languages, the latter show a good deal of instability in this respect, both between one language and another and as between two stages of the same language.

En la carta de Colón a Luis Santángel, fechada el 15 de febrero de 1493, Colón escribe que "monstruos no he hallado ni noticia, salvo de una isla que es Caribe, [...] que es poblada de una gente que tienen en todas las islas por muy feroces, los cuales comen carne humana" (Serna, 2005: 123). La misma información aparece en la carta escrita a Rafael Sánchez ese mismo año y que tuvo mucha difusión en Europa en aquella época. En la carta dice que "no observé monstruos ni llegó a mí noticia que los hubiese, exceptuando la isla llamada Caris [...]" (Fernández de Navarrete, 1986: 227). Aquí Caribe y Caris se emplean con valor geográfico.

Caribe, 'gente de cierta zona de las Antillas', adquiere con el paso del tiempo un segundo significado, el de 'gente ferozy salvaje', 'gente que come carne' o 'antropófago', debido a que Colón, en sus escritos, relaciona este pueblo con la antropofagia; y de ello se hacen eco otros cronistas de la época. Cabe tener en cuenta que los relatos de los taínos, tal como indica Henríquez Ureña, "hicieron creer a Colón que los caribes comían carne humana", y ello no les resultó difícil porque "los conquistadores traían la imaginación llena de antropófagos, amazonas, hombres con cola o con cara de perroy otros entes míticos de la antigüedad clásica o de la Edad Media" (1938: 95). Interesa en ese punto citar al erudito Cioranescu (1987: 92), quien resume que la mencionada forma caniba, que consta en el Diario de Colón, "ha producido en esp. el doblete caribe y caníbal". Y, en cuanto al significado, dice que "ambas voces tienen un doble sentido idéntico: 'indigena de las Antillas' (visto por él mismo) y 'hombre cruel, antropófago' (visto por los europeos)".

Al volver la vista hacia otros textos de la época, puede destacarse que de estos términos y de los antropófagos da cuenta Pedro Mártir de Anglería en sus Décadas del Nuevo Mundo, escritas entre 1493 y 1526. Ya en la Década Primera se halla el nombre de aquel pueblo feroz que come carne humana:

Esse non longe ab illis insulis quorundam ferorum hominum insulas, qui carnibus humanis vescantur, fama didicere: id esse causae, quod ita trepidi 
aduentantes nostros confugerent, postea retulerunt, Canibales arbitrati: sic truculentos illos, siue caribes, uocant (Mártir de Anglería, 1516: 5).

[Adquirieron noticias de que no lejos de aquellas islas, había otras de ciertos hombres feroces que se comen la carne humana, y contaron después que esa era la causa de que tan temerosos huyeran de los nuestros cuando se acercaron a sus tierras, pensando que serían caníbales; asíllaman a aquellos feroces, o caribes (Mártir de Anglería, 1989: 12)²].

Y en el siguiente fragmento se describe su ferocidad:

Los pacíficos insulares se quejan de que los caníbales asaltan perpetuamente sus islas para robarlos con continuas acometidas, no de otro modo que en los bosques los cazadores persiguen a las fieras con violencia y con trampas. A los niños que cogen, los castran como nosotros a los pollos o cerdillos que queremos criar más gordos y tiernos para comerlos; cuando se han hecho grandes y gordos, se los comen; pero a los de edad madura, cuando caen en sus manos, los matan y los parten; los intestinos y las extremidades de los miembros se las comen frescas, y los miembros los guardan para otro tiempo, salados, como nosotros los perniles de cerdo. El comerse las mujeres es entre ellos ilícito y obsceno; pero si cogen algunas jóvenes las cuidan y conservan para la procreación, no de otra manera que nosotros las gallinas, ovejas, terneras, y demás animales. A las viejas las tienen por esclavas para que les sirvan.

A continuación se vuelve a mencionar el terror que siembra la embestida de estos salvajes que comen carne humana:

Lo mismo los varones que las mujeres de las islas, que ya podemos llamar nuestras, cuando advierten que vienen los caníbales, no encuentran más salvación que la fuga. Aunque usan saetas de caña muy agudas, saben, sin embargo, que les aprovechan poco para reprimir la violencia y furor de los caníbales, pues confiesan todos los indígenas que en la lucha diez caribes vencerían fácilmente a ciento de ellos (Mártir de Anglería, 1989: 12).

Fray Ramón Pané en su Relación acerca de las antigüedades de los indios, un manuscrito de 1496, habla de los caníbales (Pané, 2004: 40, n. 132); Martín Fernández de Enciso en la Suma de geografía de 1519 escribe caníbales (Fernández de Enciso, 1519); Alonso de Chávez en su obra Quatri partitu en cosmografía práctica, y por otro nombre espejo de navegantes de aproximadamente 1527 usa tanto la forma caribes como caníbales (corde); Fernández de Oviedo escribe caribes en su Historia General y Natural de las Indias, cuya primera parte fue publicada en 1535 (Fernández de Oviedo, 1992: 34); Bartolomé de Las Casas

${ }^{2}$ Traducción española hecha por Joaquín Torres Asensio (1892) y revisada por Julio Martínez Mesanza (Mártir de Anglería, 1989: 3), texto que seguimos en las citas siguientes. 
emplea tanto caribes como caníbales en la Historia de las Indias (1527-1561), con primera publicación en 1821 (Las Casas, 1951: 228, 240); Francisco López de Gómara en La primera parte de la Historia natural de las Indias de 1554 usa la forma caribes (corde). Se trata de textos que fueron traducidos y publicados en otros países europeos a lo largo del siglo xvi y el xvii. El fragmento seleccionado y cuya trayectoria nos proponemos seguir es el antes citado que procede de la obra de Mártir de Anglería.

La voz caribe, y no caníbal, se encuentra incluida en el diccionario de Autoridades de 1729 en el que se explica que es "hombre sangriento y cruél, que se enfurece contra otros, sin tener lástima ni compasión. Es tomada la metaphora de unos Indios de la Provincia de Caribana en las Indias, donde todos se alimentaban de carne humana" (ntlle). La entrada caníbal no aparece en el diccionario de la academia hasta 1838 y remite a la entrada caribe como sinónimo; en 1869 aparece por primera vez con una definición, la de 'nombre dado a los antropófagos de América' (ntlle). Fue en el siglo xix cuando caribe en el sentido de ‘antropófago'se reemplazó por caníbal (ntlle). Según Henríquez Ureña y Perissinotto, este reemplazo se debe a la influencia del francés y del inglés, lenguas en las que caníbal se habia generalizado además de pasar al lenguaje científico (Henríquez Ureña, 1938: 96; Perissinotto, 1987:300; tlfi; oed).

En el español general, caribe tiene ahora valor etnográfico-lingüístico y ha adquirido significación geográfica, como observa Henríquez Ureña (1938: 100). Así, según la vigésima segunda edición del drae, hoy la principal acepción de caribe es la de "individuo de un pueblo que en otro tiempo dominó una parte de las Antillas y se extendió por el norte de América del Sur" (drae, 2001: 454; drae, 2014). Y la primera acepción de caníbal es 'antropófago', la segunda es 'salvajes de las Antillas que comían carne humana'y la tercera 'hombre cruel y feroz' (drae, 2001: 425; drae, 2014).

Si resumimos, entonces, la trayectoria de los dos lexemas en la lengua española, cabe decir que en el siglo xvi, caníbal y caribe son sinónimos; luego caribe se populariza y cae en desuso caníbal a la vez que caribe adquiere el valor de 'antropófago'. En el siglo xix, caníbal desplaza la forma caribe en el sentido de 'antropófago' y caribe adopta el valor gentilicio y toponímico (Friederici, 1960: 143-145; Perissinotto, 1987: 289-295; Parodi, 2009: 37-41; Moromisato, 2009: 81-91).

\section{Canibali en libretto y en PaeSi novamenti retrovati}

La noticia sobre la expedición de Colón a ultramar llegó a Italia en 1493 y ese mismo año la carta de Colón a Rafael Sánchez se tradujo al toscano, el dialecto de Florencia, y se imprimió tres veces en Italia (Serna, 2005: 117; 
Sanz 1958: xiii). En la traducción italiana, en verso, se menciona "una isola [...]. In nella quale sta gente uilana" de la que se dice "che mangia carne humana" (Sanz, 1958: xiv/7). En la traducción no aparece, sin embargo, la denominación específica para esta gente antropófaga.

Según el deli (2008: 286), el término canabali tiene registro en la lengua italiana desde 1494; posiblemente se refiere aquí a la carta escrita por el savonés Miguel Cúneo, que estuvo en el segundo viaje de Colón. Cúneo relató su experiencia en una carta escrita en 1494, destinada a Gerónimo Annari, en la que alude a los canaballi y camballi (Morales Padrón, 1990: 142, n. 4) que poblaban una isla cerca de la isla Santa María Galante.

Vespucio, en sus escritos fechados a principios del siglo xvi, emplea alternativamente las formas carabi y camballo para referirse, por un lado, a los nativos de unas tierras desconocidas y, por el otro, a los antropófagos (Perissinotto, 1987: 298). Las cartas de Vespucio se tradujeron a varias lenguas europeas y también se incorporaron en colecciones de relatos de viajes como, por ejemplo, la de Montalboddo; obra de la que hablaremos más adelante.

Analizaremos a continuación el Libretto de tutta la navigazione del Re de Spagna de le isole e terreni novamente trovati (Libretto), un resumen en italiano de los nueve primeros capítulos de la Década Primera de Pedro Mártir de Angleria, publicado en Venecia en 1504 (Wroth/Libretto, 1504). Se trata de la traducción de una copia que Mártir de Anglería había entregado al veneciano Angelo Trivigiano, secretario de Domenico Pisani, el embajador en la corte española de la República de Venecia.

En este texto aparecen dos vocablos amerindios, y uno de ellos es caníbal, voz usada para referirse a las gentes que vivían en "alcũe isole» ubicadas "[...] non molto lõtano da quella isola" y que eran "crudelissimi hoí che se passeno de carne humana" por ellos llamados canibali: "quelli homini quali chiamauano Canibali [...]" (Wroth/Libretto, 1930: 4). Los nativos de otras islas se quejaban de esta gente feroz que comía carne humana: "[...] se lamẽtauano li poueri homini che non altramẽte sono uexati da questi canibali: come sere saluatiche da tigri \& leoni" y explicaban a Colón y sus compañeros cómo trataban a los jóvenes si los captaban: «li garzoni che loro prẽdeno licastrano: come faciamo noi castrati: perche diuentano piu grassi per mazarli"; también daban cuenta del maltrato que recibian los hombres adultos por ellos capturados: "li homini maturi cosi come li prẽdeno li amazano: \& mangiano: \& mangiano freschi le intestini \& li extremi: mẽbra del copro. El resto insalano:\& liseruano ali soi tẽpi come faciamo noi" y las mujeres: "li presiuti le donne non mãzano: ma le saluano affar figlioli: non altrimente come faciamo noi. Galine per uoui: le uechie usano per schiaue" (Wroth/Libretto, 1930: 4). A continuación se explica que si se 
acercaban "questi canibali» los indígenas pacíficos "nõ trouano altra salute che fugire" por "el furore \& la rabia de quelli" pues "trouano: che poco gli zouano:\& confessano che .x. canibali che si trouano .100. de loro li supano" (Wroth/Libretto, 1930: 4).

El texto del Libretto fue incluido poco después en la colección de relaciones de viajes confeccionada por Fracanzano da Montalboddo, lanzada en 1507 con el título Paesi novamente retrovati. Et Novo Mondo da Alberico Vesputio (Paesi novamente retrovati) (Böhme, 1962: 19; Henschel, 2005: 77, 91)3. Se trata de una obra que se difundió por toda Europa y que fue traducida a varias lenguas: latín, alemán y francés. Como queda mencionado, el texto de las dos obras es el mismo. La descripción de los caribes arriba expuesta procede del Libretto; la siguiente la extraemos de Paesi novamente retrovati:

Et se lamentauano li poueri homini che non altramente sonno uexati da questi canibali: come sere saluatiche da tigri \& leoni: li garzoni che loro prendeno li castrano: come faciamo noi castrati: perche diuentano piu grassi per mazarli:\& li homini maturi cosi come li prendeno li amazano:\& mãgiano freschi le intestini \& li extremi membra del corpo. El resto insalano:\&li seruano ali soi tēpi come faciamo noi: li presiuti le donne non le manzano: ma lesaluano affar figlioli: non altramente como faciamo nui. Galine per uoui: le uechie usano per schiaue. De le isole che ormai potemo repuar nostre: cosi li homini come le femene: come presentano questi canibali approximare aloro: non trouano aloro: nō trouano altra salute que fugire: anchora che usino facete acutissime: tamen ariprimare el furore \& la rabia de quelli trouano: che pocho gli zouano:\& confessano che .x. canibali che si trouano .c. deloro li superão (Montalboddo, 1507) .

Tanto en el Libretto como en Paesi novamente retrovati se usa la forma canibali, término, según Danesi (1976: 115), que el traductor ha adaptado al italiano de la época añadiendo la vocal /-i/, que también es el morfema de plural en la lengua receptora. Se trata de una forma que aparece igualmente en la traducción alemana del texto de Montalboddo, tal como veremos más adelante. Interesa mencionar que en la traducción italiana del texto en cuestión solo aparece la forma canibali y nunca la forma caribe. Ahora bien, en los textos manejados, canibali se refiere al pueblo indígena de las Antillas y a veces también aparece como designación geográfica. La forma actual italiana es cannibale, cuyo significado es 'antropofago, uomo feroce'. La fuente italiana consultada explica que cannibale es alteración de caribal, que viene

\footnotetext{
${ }^{3}$ El cuarto libro de la colección habla del descubrimiento de América.

${ }^{4}$ Se trata de un resumen de una parte del primer capítulo de la Década Primera de Mártir de Anglería de donde procede el antes expuesto fragmento: "Los pacíficos insulares se quejan de que los caníbales asaltan perpetuamente sus islas para robarlos con continuas acometidas..." (Mártir de Anglería, 1989: 12).
} 
de caribe y originalmente de la lengua caribe; constata asimismo que la voz pasa al italiano por mediación del español (deli, 2008: 286; Nocentini, 2010: 179). Por otro lado, caribo o caraibo tiene en el italiano moderno un valor etnogeográfico (Zingarelli, 2002: 312).

\section{Canibali y Canibalen en newe unbekanthe landte... y en new welt...}

En Alemania se menciona a los antropófagos del Nuevo Mundo a partir de 1497, pero la palabra propiamente no figura en textos hasta 1508. Así, en Kolumbus-Brief 5 , la carta de Colón, de 1497, solo se lee "wilde lüt die essent menschen fleisch", esto es, 'gente salvaje que come carne humana' (Palmer, 1939: 63). La carta se tradujo del español (Palmer, 1939: 63), del catalán y/oel latín (Harrisse, 1894: 8-9; Sanz, 1958: xii/ 14) o del españoly el latín (Henschel, 2005: 283).

La voz amerindia aparece por primera vez en la traducción de la colección de relaciones de viajes Paesi novamente retrovati del italiano Fracanzano da Montalboddo, titulada en alemán Newe unbekanthe landte und ein newe weldte in kurtz vergenger zeythe erfunden (Newe unbekanthe landte) traducida por Jobst Ruchamer y publicada en Núremberg en 1508 (Henschel, 2005: 111; Sadji, 1983; Ankenbauer, 2010: 58) ${ }^{6}$. En este texto se halla la forma italiana canibali, tal como se ve en la siguiente cita: "Als sie die unsern sahen / die fluchte namen / wenn die gedachten / wir weren der selbigen lewte / welche genant sein Canibalin; cita que procede del capitulo lxxxviii, cuyo título es precisamente "võ den sitthen / wesen / und gebrauchen dises volckes Canibali" (Sadji, 1983: Newe unbekanthe landte). El vocablo aparece aquí con el valor de 'pueblo' o 'gente', pero conviene tener en cuenta que antes de la primera aparición del indoamericanismo en este texto se habla de gente feroz que come carne humana: "Wir vernamen auch das nicht weyte von diser Inseln, waren etliche Inseln / in welchen vast grawsame lewthe wonthen / die selbigen essen menschen fleysch" (Sadji, 1983: Newe unbekanthe landte). Esta información relaciona esta gente, los canibali, con la antropofagia y semejante es la manera de hablar de la gente canibali en el fragmento que reproducimos a continuación; cabe indicar que se trata del mismo pasaje que antes citamos en la traducción española e italiana:

${ }^{5}$ Título completo: Eyn schoen hübsch lesen von etlichen inßlen die do in kurtzen zyten funden synd durch den künig von hispania, vnd sagt von großen wunderlichen dingen die in den selben inßlen synd.

${ }^{6}$ Este mismo año (1508) el Paesi novamente retrovati se publicó en bajo alemán con el título Nye unbekande lande Unde eine nye Werldt in korter vorgangener tyd gefunden; el traductor fue Henning Ghetelen (Böhme, 1962: 35-36; Ankenbauer, 2010: 59). No hemos tenido acceso a esta traducción. 
Dise arme lewte/beklagten sich zu mal sere/wie sie belastiget vnd gepeyniget wern von disen Canibali/ nicht anderst dañ wie die wilden thiere veruolget weren/von den Tyger thieren/und Löwen/ Die jungen knechte/so sie die selbigen gefangen haben/so verschneyden sie dañ die selbigen/wie wir thun den hemeln/auff das/das sie dester vayster sollen werden zu tódten. So sie aber einen manne vahen/so tódten sie jnen also wie er ist/vnd essen sein gederme also frische Deß gleychen seyne außerliche glider seines leybs/als hendt und fuß. Und das ander tayle des kórpers einsalzen sie/vnd behalten es biß zu seyner zeythe/gleych als wir thun mit dem fleysch. So sie aber weyber vahen/die selbigen essen sie nicht/sie behaltens aber auff das/das sie kinder sollen tragen/ nicht anderst dañ als wir die hennen halten vmb der ayer willen/vnd die altenn weyber gebrauchen sie fur Sclaue/das ist/ zu dienerin zu aller herten arbeythe/ Die jnwoner diser Inseln/ samentlich manne und frawen/so sie vermerken oder erkennen/das die canibali jnen wollen zu nehmen/so wissen sie jnsebst keyn andere erlösunge/oder frystunge jres lebens/dañ die fluchte. Dises volcke gebraucht auch waffen/das sein vast scharpffe lengleyn/Aber zu widersteen dem grymmigen wüthen diser Canibale/ hilffte es sie gar wenig. Dises volcke sagte auch/so der Canibali zehen/uberkomen der jren hundert so vberwundten sie zehen Canibali/der jren hunderte (Sadji, 1983: Newe unbekanthe landte).

Este mismo texto se encuentra también en Simon Grynäus New welt der landschaften vnnd Jnsulen, so bis hie her allen Altweltsbeschrybern vnbekant... de 1534. Se trata de la traducción de Michael Herr a partir de la versión latina de Paesi novamente retrovati (Böhme, 1962: 60-62). Aquí, igual que en la otra traducción que hemos estudiado, se relaciona el pueblo salvaje con la antropofagia: "Canibali heissen die selben/ die menschen fleisch essen" (Grynäus, 1534). Y del capítulo "von den sitten der Canibalen" procede el siguiente pasaje, similar aunque no igual al de la cita anterior:

Diese Klagtẽ vns trawriglich von denen grewlichen gewonheiten / dã sie sagten / wie sie nit anders vber sie wütteden dã wie ein Tyger thier oder ein Lew vber ein zams schefflin thut/ das grewlich zu sagen ist/ dã wo sie ein jungen knaben vberkommen / so schneiden sie im die hoden aus / und mesten jhn wie ein capaunen / das sie dester besser zu essen seyen. Die mã schlachten si so bald / vnd wẽ sie die selbẽ entweiden / so essend sie das geweid grien / auch hend vñ füs mit dem kopff / das vbrig salzen sie / und behaltens / wie wir das durr fleisch vnd würst. Die weyber essen sie nicht / sundern sie behalten sie zum mehr machen / wie wir die hennen. Die alten halten sie fur meid / darumb so wir zu disen Inseln kommen / so fliehen sie schnel dñ sie meinen das grewlich volck kum zu jnẽ. Vnd wie wol sie bogen und geschos haben / so sind sie doch nit so starck / das sis sie dẽmen mochten / dñ zehen Canibali vertriebẽ jnen hundert / darumb behelffen sie sich gegẽ jnen allein mit de flucht (Grynäus, 1534).

En estas traducciones aparece también la forma Canibalen o sea la palabra prestada pero ya con la desinencia alemana -(e)n-marca de pluralidad-, 
lo cual indica su inicial proceso de adaptación al sistema gramatical de la lengua receptora. Interesa mencionar asimismo que en el texto que sigue al relato sobre Colón, la carta de Pedro Alonso Niño (1499), prevalece esta forma semiadaptada, canibalen. Conviene notar que en la traducción alemana de los dos textos, el del Libretto y del de Montalboddo, solo aparece la forma canibali o canibalen y nunca la forma caribe.

Las formas Canibaliy Canibalen son de uso general en la lengua alemana hasta principios del siglo xix; sin embargo, aparecen esporádicamente formas como Charaibi, Caribes, charybes, canibalianer y canibelless que se usaban indistintamente para referirse, por un lado, a un 'antropófago' y, por el otro, a 'gente salvaje de las Antillas' (Palmer, 1939: 63). Con el paso del tiempo y quizá por influencia de otras lenguas, los dos significantes llegaron a concretar y especializar su significado y llegaron, a la vez, a ser dos palabras independientes, dos significantes con dos significados distintos.

La forma actual, Kannibale, que hoy significa 'Menschenfresser', 'animal que come carne de la propia especie', existe desde el siglo xvii (Palmer, 1939: 63). Karibe tiene en el alemán moderno un valor etnográfico, y Karibik, geográfico (Duden, 1990: 2062; Kluge, 1999: 422).

\section{Canibalister en geograPhia hiStorica Orientalis}

Hans Hansen Skonning, o Skoning (1579-1651), fue impresor en Aarhus (Dinamarca) en el siglo xvii y publicó en 1641 un libro de geografia titulado Geographia Historica Orientalis. Det er Atskillige Østerske Landis oc Øers / met deß Folcis Beskriffvelse: Nemlig / Tyrckers / Jøders / Grækers / Egypters / Indianers / Persianers / oc andre flere Landskabers underlige Sæder / Tro / Religion / Lower oc selsom Lands Maneer [De países e islas orientales, incluida la descripción de sus habitantes: o sea, de los turcos, los judios, los griegos, los egipcios, los indios, los persas, así como la descripción de las costumbres extrañas de otros países, la creencia, la religión, las leyes y diferente comportamiento de la gente] ${ }^{7}$.

Para confeccionar el libro, Hansen Skonning se apoyó, entre otras obras, en el texto Omnium gentium mores, leges et ritus de Johannes Boemus, del que se realizaron 29 ediciones entre 1520 y 1629; también en el Amphiteatro Naturae, obra compilada por el impresor alemán Georg Beatus y publicada en Fráncfort entre 1580 y 1632 (Horstbøll, 1999: 506). No se puede descartar que utilizara otras fuentes alemanas a las que podía tener acceso a través de su trabajo, pues mantenía contacto con una imprenta en Rostock, Alemania, país que visitaba con frecuencia por motivos de trabajo (Elkjær y Dehnist, 1988: 8, 21; Sejr, 1942).

\footnotetext{
${ }^{7}$ La traducción es nuestra.
} 
El capítulo lxiii del mencionado libro danés se titula "Kort Udtog eller Extract til en Bestlutning / om Columbi oc Vesputii Seiglaß Reisge fra Hispanien / oc udi Americam, til de ny funden Øer: Met huis underlige dennem er vederfaret oc hændet paa samme Reygse", es decir: 'Para concluir: un corto resumen o extracto de la navegación de Colón y Vespucio desde España hasta las islas recién encontradas en América: sobre lo extraño que les sucedió en el viaje'. Se trata efectivamente del último capítulo del libro en el que aparece un resumen de las peripecias y las aventuras de Colón y Vespucio allende del mar. El relato sobre Colón llena diez páginas; la sección dedicada a la figura de Vespucio es de nueve páginas. En las relaciones se describe la naturaleza, la flora y la fauna, así como los habitantes de las tierras encontradas. También hay descripción de los caníbales, de sus costumbres antropofágicas, se relata además el encuentro hostil entre estos y los europeos.

El indoamericanismo caníbal solo aparece en la relación sobre Colón. El pasaje seleccionado relata que los isleños pacíficos se quejaban de gente llamada Canibalister: "it slags Folck/ som kaldis Canibalister" (Hansen Skonning, 1641: 767) que a veces salia de su tierra para asaltar otras. A continuación se explica cómo mataban a los capturados para luego comérselos: "fangede oc sloge Mennisken ihiel/ oc siden ode dem" (Hansen Skonning, 1641: 767). Sigue la relación con una descripción del maltrato de los jóvenes: "De unge Mandkión skaare de ud som andre Capuner/ oc mæstede dem til de bleffve fæde/ oc saa slactede dem" [A los jóvenes los castraban como se hace con los capones y los cebaron para engordarlos y luego los mataban] (Hansen Skonning, 1641:767), y seguidamente una explicación de cómo mataban alas víctimas adultas: "De bedagede Folck/ dem slacktede de strax/ skaare dem op/ kaste Tarmene oc Indvolerne bort/ det andet Kiød ode de/ saa vel som baade Hænder oc Føderne paa dennem. Huad de leffnede til offvers / det saltede de/ oc sætte hen" [Los de la edad madura los mataban inmediatamente, los partian, tiraban las tripas y los intestinos, y se comían la carne, y también las manos y los pies, lo que sobraba lo guardaban salado] (Hansen Skonning, 1641:767-768). A continuación aparece en danés el fragmento que más arriba hemos citado en español, italiano y alemán:

[...] beklagede Indvonerne sammesteds sig faare der offver/ at de lede en suar Fortrængsel oc stor Skade aff it slags folck/ som kaldis Canibalister: huorledis disse slæmme Mennisker/droge undertiden ud aff deris Land/ oc faldt ind/ baade paa dem/ oc andre Orter/ fangede oc sloge Mennisken ihiel/ oc siden ode dem/ handlede sig ey anderledis / end som Tiger Diurit oc Løwen imod de samme Diur. De unge Mandkiøn skaare de ud som andre Capuner/ oc mæstede dem til de bleffve fæde/ oc saa slactede dem. De bedagede Folck/ dem slacktede de strax/ skaare dem op/ kaste Tarmene oc Indvolerne bort/ det andet Kiød ode de/ saa vel som baade Hænder oc Føderne paa dennem. 
huad de leffnede til offvers / det saltede de oc satte hen. De unge Quindfolck holde de at faae Børn aff/ som mand holder andre Høns/ for Egẽ skyld/ huilcke Børn de ocsaa med Tiden slacktede. De ode ingen Quindfolck/ mens holt dem til den brug som sagt er/ de udgamle Quinder/ brugte de til Trældom oc Arbede. Oc naar disse Canabalister komme til denne Øe/ rømmer oc undflyer huer Mand fra dennem/ thi de ere arrige oc grumme/ oc gruelige stærcke/ saa 20. aff disse Dieffelske Mennisker/ kunde vel slaa Hunder aff de andre (Hansen Skonning, 1641: 768-769).

[Los habitantes se quejaron de que sufrian una fuerte represión y un gran daño por parte de gente llamada caníbales: de tal manera que estas personas crueles se desplazaban a veces y salian de su país / y los asaltaban/tanto a ellos como a los de otros lugares / capturaron y mataron a las personas / y luego se las comían/ procediendo de igual manera que el tigre y el león frente a animales de la misma raza/ A los jóvenes los castraban como se hace con los capones y los cebaron para engordarlos y luego los mataban/ Los de la edad madura los mataban inmediatamente/ los partian, tiraban las tripas y los intestinos / y se comían la carne, y también las manos y los pies / lo que sobraba lo guardaban salado. Las jóvenes las conservan para tener niños/ no de otra manera que las gallinas para los huevos/ los cuales niños mataban más adelante. No comían a las mujeres, sino las tenian para lo que se dice/ a las viejas las tenian por esclavas para trabajar. Y cuando estos caníbales vienen a esta isla/ [los isleños] se fugan y huyen de ellos porque son coléricos y crueles / y son horrorosamente fuertes / tanto que 20 de estos hombres diabólicos / bien podrían matar a cien de ellos].

Si se compara el extracto danés con la traducción alemana del texto de Montalboddo, puede sorprender la similitud entre las versiones. De hecho, el resumen danés parece basarse en una traducción alemana de la obra de Pedro Mártir de Anglería, del Libretto o del cuarto capítulo de la obra de Montalboddo; se trata del contenido de los dos primeros capítulos de la Primera Década y/o del resumen que se encuentra en el Libretto y Paesi novamente retrovati de Montalboddo. La colección de Montalboddo se encuentra en la traducción de Jobst Ruchamer de 1508 y ese mismo año saldría a la luz también en bajo-alemán, y luego en la de Michael Herr de 1534 (en la obra de Simon Grynäus). No descartamos que una de estas obras le haya servido a Skonning para confeccionar su propio compendio en danés.

Volviendo al vocablo canibalister, cabe decir que, en el texto danés, se refiere a los habitantes de cierta tierra. E igual que en el texto alemán, la voz se emplea con el valor gentilicio y en contadas ocasiones como topónimo. Sin embargo, la gente del Caribe se relaciona a menudo con la antropofagia igual que en los textos antes estudiados. En cualquier caso, en la traducción danesa del texto en cuestión, solo aparece la forma canibalister o canabalister (en pocas ocasiones canibalisters, que con la desinencia -s marca el genitivo), y nunca la forma caribe. 
Al consultar el diccionario danés, ods, se nos refiere que la voz es registrada por primera vez en un vocabulario manuscrito confeccionado por el danés Matthias Moth hacia 1700 (ods, 1975: 1203-1204). El hallazgo del libro de Skonning permitiría enmendar la información ofrecida por las fuentes lexicográficas danesas, pues no descartamos en absoluto la idea de que el texto danés aquí objeto de estudio sea la primera documentación del vocablo en la lengua danesa.

En el citado diccionario la acepción de la voz kannibal es 'det folk [...], som æde Mennisker', es decir, 'gente que come carne humana'. Informa, sin embargo, que, hacia finales del siglo xviii, la voz aparece también con el significado de 'persona feroz y bárbara'. Y en 1919 se documenta con el valor de 'animales que comen a los de su propia raza'.

En cuanto a la forma Kariber, o Kareiber, cabe señalar que aparece con un registro de 1700 en el mencionado vocabulario de Moth y con el significado: 'pueblo de América'. No obstante, la forma basada en caníbal —Cannibaler, Canibal, Kanibal, Kannibal - prevalece y actualmente se usa kannibal junto con la palabra danesa menneskeæder, 'antropófago' (ods; Nielsen, 1995: 282; Politiken, 2000a: 693; Politiken, 2000b: 343).

Por lo que se refiere a las formas caraibier o caribier y caraibisk o caribisk, cabe decir que solo tienen valor etnológico y geográfico, respectivamente (Hårbøl, Schack y Spang-Hanssen, 1997: 140).

\section{CanibaliStar en ein ágæt, nytSöm, fróðleg, lyStileg [...] bók}

En un manuscrito islandés de 1660[80?] titulado Ein ágæt, nytsöm, fróðleg, lystileg, skemmtiríkog artug bók... (Jónsson, 1660-[80]) se encuentran dos textos cortos relacionados con el descubrimiento de las nuevas tierras americanas. Uno es "Páttur af Colombo um hans landa uppleitan og ókunnar siglingar" [Relato sobre Colón, sus navegaciones y descubrimientos] que a lo largo de ocho páginas relata la expedición de Colón y su contacto con los indígenas, sobre todo con los caníbales. El otro es un relato sobre Vespucio, sus navegaciones y encuentros con los aborígenes, intitulado "Americi Vesputii páttur um hans siglingar og landa uppleitun" [Relato sobre Amérigo Vespucio y sus navegaciones y descubrimientos], de unas siete páginas. Sabemos que estos dos relatos han sido traducidos del antes mencionado texto danés Kort Udtog eller Extract til en Beslutning/om Colombi oc Vesputii Seiglaß Reigse fra Hispanien/ oc udi Americam, til de ny funden Øer: Met huis underlige dennem er vederfaret oc hændet paa samme Reygse.

El traductor, Magnús Jónsson, por sobrenombre El gordo, campesino y erudito, vivió en la isla Vigur en Ísafjarđardjúp, en los Fiordos Norocciden-

\footnotetext{
${ }^{8}$ Un buen libro y útil, interesante, alegre, divertido y agradable...
} 
tales ${ }^{9}$. Se dedicó entre otras cosas a la labor de traducir y transcribir libros y manuscritos. Se sabe que hablaba y leía latín y danés, y sabía algo de alemán. Tenía una gran colección de libros y manuscritos y es posible que entre los libros de su biblioteca se encontrara la mencionada obra del danés Skonning que hemos mencionado en el apartado anterior (Ólafsson, 1956).

Veamos la traducción islandesa de la relación sobre Colón. Igual que en el texto danés, es solo en esta relación vinculada con el personaje de Colón en la que aparece la palabra caníbal. Partiendo del pasaje seleccionado cabe decir que se trata de la misma materia narrativa, pues se expone el encuentro con los indígenas pacíficos, que manifiestan su miedo por un pueblo guerrero y feroz denominado canibalister: "ad peir lidu störn skada og ÿfrgäng af pví fölke, sem kallast Canibalister» (nótese que la forma del vocablo es la danesa). Volviendo a la relación, pues, los isleños pacíficos explican que esta otra gente feroz sale a menudo y hace incursiones en otras tierras, captura humanos, los mata y luego se los come: «kvädu pær slæmú manneskiúr færi oft af synú lande til pessra og annara, tæke foolk til fänga og deiddi, æte pad sÿdn" [Decían que esta gente nefasta salía más a menudo de su tierra hacia esta y otras, apresaba los isleños y los mataba para luego comérselos]. No falta en el texto islandés la descripción del tratamiento de los jóvenes: "pær úngú manneskiúr færdi peir med sier og eldi pær, par til pær vær ordnar feitar, og slátrúdú peim so sier til sælgætis ađ ieta" [A la gente joven se la llevaba y cebía para engordarla, y luego la mataba para comer la exquisitez] ni tampoco la de los adultos: "gómlú fölke slätrudu peir strax, snórúdú búrt inniflúm en kióted æti peir so vel hendúr og fætúr, en pad peir leÿfdu, sólltudu peir nidr og geimdú" [Mataban en seguida a los viejos, les quitaban y tiraban los intestinos pero sí comían la carne, así como las manos y los pies, y lo que quedaba guardaban salado] (Hansen Skonning, 1660-80: 2r). Seguidamente aparece en islandés el ya conocido fragmento que antes hemos citado en español, italiano, alemán y danés:

Sem Colúmbús var nú ä peirri Eÿ med sitt foolk, pä bärú landsmenn sig úpp fyrir honum, ad peir lide störan skada og ÿfrgäng af pví fölke, sem kallast Canibalister, kvädu pær slæmu manneskiúr færi oft af synú lande til pessara og annara, tæke foolk til fänga og deiddi, æte pad sÿdn, og hóndlúdú vid pad mÿskúnnarlaúst sem öargadÿr; pær úngú manneskiúr færdi peir med sier og eldi pær, par til pær vær ordnar feitar, og slátrúdú peim so sier til sælgæitis ađ ieta, gómlú fölke slätrúdú peir strax, snórúdú búrt inniflúm en kióted æti peir so vel hendúr og fætúr, en pad peir leÿfdu, söltúdú peir nidr

${ }^{9}$ Durante el siglo xvii había mucho contacto entre los islandeses y los pescadores del continente europeo, franceses, españoles, vascos, alemanes y otros que venían a aguas islandesas con el fin de pescar ballena y bacalao. Fruto del contacto directo del pueblo islandés y el hispano-vasco es el vocabulario vasco-islandés que data de finales del siglo xvii. 
og geimdú, únga kvennmenn hielldú peir til pess ad eiga bórn, hver bórn peir eirnin aflÿfúdú ad ieta, ongva kvennmenn vilia peir ieta, en hafa pä til pess, sem sagt er, gamlar konr brúka peir til prældöms og ervidis (Hansen Skonning, 1660-80: 2r).

[Estando Colón y su gente en aquella isla, se quejaron los nativos de que sufrían un gran daño y agresión por parte de gente llamada caníbales, decían que era gente cruel que a menudo salia de su país hacia este y otros, cogía gente y mataba, luego se la comía y la trataba inhumanamente como a las fieras, a los jóvenes que cogían, los criaban para ser más gordos, los mataban y luego se los comían como si se tratara de una exquisitez. A los viejos los mataban inmediatamente, les quitaban los intestinos y tiraban pero comían la carne, así como las manos y los pies, lo que quedaba lo guardaban salado. Las jóvenes las tenían para tener niños, los cuales también mataban para comérselos. No quieren comer a las mujeres, sino que las tenían para lo que se dice, a las mujeres viejas las usan como esclavas para trabajar].

Interesa indicar que la segunda forma del vocablo estudiado que aparece en el texto islandés es canabalistar, tal como se observa en la siguiente cita: "og nær pessir Canabalistar kiæme par ä Eÿúna, flÿdi hver madr i sköga og filsne, pví peir være grimmer og hardúdúgt fölk, og par med sterkir, so 20. af peim giæte fängad ogÿfirúnned 100. eÿamanna edr pessa lands innbiggiara» [Y cuando estos caníbales llegaban a la isla, se dieron todos los habitantes a la fuga y se escondian en los bosques y en cobijos, porque era gente cruel $\mathrm{y}$ feroz, y también fuerte, así veinte de ellos podian cautivar y vencer a cien isleños o habitantes de esta tierra].

En este caso el sufijo se ha adaptado al islandés -istar en lugar del sufijo danés, -ister. La tercera forma del vocablo hallada en esta traducción es canabalista, la cual expresa varios casos del singular y plural; se trata por tanto de un ejemplo de cómo el traductor adapta la voz extranjera al sistema gramatical islandés. Por otra parte, en la traducción islandesa del texto estudiado solo aparece la forma canibalister o canabalistar (esta última es la que prevalece), y nunca la forma caribe.

La palabra islandesa mannæta, que figura en textos de los siglos xvi y xvii (roh), tiene su origen en la forma greco-latina, igual que la forma danesa menneskeæder, 'persona que come carne humana'; por lo tanto no se puede relacionar con la voz indoamericana caníbal que no ha sido incorporada a la lengua islandesa aunque se use esporádicamente en la lengua oral. De hecho son pocos los textos islandeses en los que aparece este término indoamericano. Uno data de 1930, fecha en la que se registra la forma Kannibalar con el valor de 'gente o personas poco civilizadas' (Spegilinn, 1930: 152). La voz aparece asimismo en la traducción al islandés del Diario de Colón publicada en 1992 bajo la forma kanníbali (Kólumbus, 1992: 66). 
El sustantivo Karíbar (singular: Karíbi) es la forma actual islandesa para designar el pueblo caribe (íao, 1990: 245); el adjetivo karabískur, 'caribeño', se encuentra en la lengua desde finales del siglo xviii o principios del siglo xix; en aquella época su forma era caraibiskur (roh).

\section{Consideraciones finales}

En las páginas precedentes hemos seguido la trayectoria, desde el sur hasta el norte europeos, de un texto escrito en España hacia finales del siglo xv. Se trata de una parte de la Década Primera de Pedro Mártir de Anglería, texto que, sin conocimiento ni permiso del autor, fue resumidoy traducido al italiano por Angelo Trivigiano y luego publicado en Italia en 1504 bajo el título Libretto de tutta la navigazione del Re de Spagna de le isole e terreni novamente trovati. Contiene la relación de los tres primeros viajes de Colón a las Indias Occidentales, así como la expedición de Pedro Alonso Niño y la de Vicente Yáñez en 1499.

El Libretto fue incluido en la colección de relaciones de viajes de Fracanzano da Montalboddo, Paesi novamente retrovati, que salió a la luz en Italia en 1507. Esta colección, por otra parte, fue traducida al alemán por Jobst Ruchamer y publicada en Núremberg en 1508. Ese mismo año se imprimió también la traducción bajo-alemana en la misma ciudad. Y desde 1508 existe asimismo una traducción latina de esta colección de Montalboddo, que figura, entre muchos otros relatos, en Novus Orbis Regionum (publicada en Basilea en 1532) de Simon Grynaeus y Johann Huttich, obra traducida por Michael Herr al alemán e impresa en Estrasburgo en 1534.

Una de estas traducciones alemanas del mencionado texto parece haber sido la base del resumen hecho por el danés Hans Hansen Skonning sobre Colón (y Vespucio) y que constituye elúltimo capítulo de su libro Geographia Historica Orientalis publicado en 1641. Este resumen fue luego traducido al islandés en la segunda mitad del siglo xvii y se halla en el manuscrito Ein ágæt, nytsöm, fróðleg, lystileg, skemmtirík og artug bók... (Jónsson, 1660-[80]).

No cabe la menor duda de que la información sobre los caníbales y su proceder arranca de la pluma de Pedro Mártir de Anglería, pues es sabido que no aparece semejante descripción de esta gente en los escritos de Colón, y además la comparación que hemos realizado de los textos estudiados y comentados aquí no deja lugar a dudas en ese mismo sentido.

Nuestra indagación nos ha permitido constatar que en las lenguas germánicas la forma caníbal prevalece desde el primer momento de acogida con el significado de 'pueblo, gente', significado que luego es desplazado por el de 'antropófago' en todas las lenguas que aquí hemos estudiado, menos en el islandés. En ninguno de los textos estudiados aparece la forma caribe, 
debido probablemente a la decisión del primer traductor, Angelo Trivigiano, quien no incluyó sino la primera forma de las dos que había apuntado Mártir de Anglería en su Década Primera, es decir, caníbal y caribe. En las lenguas aquí estudiadas, caníbal ha extendido su significado, de modo que abraza acepciones ampliadas del tipo 'animal que come carne de los de su misma especie', 'persona feroz y cruel', y 'una persona bárbara e inmoral'. Caribe se utiliza, en cambio, como gentilicio y topónimo.

En estas páginas también hemos pretendido trazar el camino seguido por la denominación autóctona para este pueblo indígena de las Antillas Menores que supuestamente comía carne humana, desde la lengua emisora, a través de las lenguas receptoras y transmisoras —español, italiano y alemán— hasta su llegada a las lenguas danesa e islandesa. El recorrido de la voz amerindia es el mismo que el del texto: desde España por Italia, Alemania, Dinamarca y hasta Islandia.

En el proceso de incorporación de la voz amerindia observamos que caníbal se registra en las lenguas española e italiana hacia finales del siglo xv; en alemán tiene documentación desde principios del siglo xvi; en danés e islandés aparece en textos del siglo xvii. El trayecto europeo que siguió la palabra amerindia de sur a norte se tomó, pues, entre un sigloy medioy dos siglos.

\section{Bibliografia}

Ankenbauer, N. (2010): «Das ich mochte meer newer dyng erfaren». Die Versprachlichung des Neuen in den Paesi novamente retrovati (Vicenza, 1507) und in ihrer deutschen Übersetzung (Nürnberg, 1508). Berlin, Frank \& Timme.

Böhme, M. (1962): Die grossen Reisesammlungen des 16. Jahrhunderts und ihre Bedeutung. Amsterdam, Meridian.

Buesa Oliver, T. y Enguita Utrilla, J.M. (1992): Léxico del español de América: su elemento patrimonial e indígena. Madrid, Mapfre.

Cioranescu, A. (1987): Los hispanismos en el francés clásico. Madrid, rae.

Colón, C. (1996): Los cuatro viajes. Testamento. C. Varela (ed.). Madrid, Alianza.

- (2005): "Carta a Luis de Santángel». M. Serna (ed.): Crónicas de Indias. Madrid, Cátedra, págs. 117-125.

corde = Real Academia Española: Corpus diacrónico del español (corde) (banco de datos en linea: <http://www.rae.es> [consulta: 10 de octubre de 2016]).

Danesi, M. (1976): «Early Indoamericanisms in Italian: The Itinerario of Juan de Grijalva". Orbis, 20, págs. 109-120.

deli = Cortelazzo, M. y Zolli, P. (2008): Dizionario Etimologico della Lingua Italiana . Bologna, Zanichelli.

drae $=$ Real Academia Española (2001, 2014): Diccionario de la lengua española . Madrid, Espasa Calpe (enlínea: <www.rae.es> [consulta: 10 de octubrede 2016]). 
Duden (1990): Fremdwörterbuch. Mannheim-Leipzig-Viena-Zürich, Duden.

Elkjær, K. y Dehnist, L. (1988): Bogtrykkeren Hans Hansen Skonning. Århus, Særtryk af Århus Stifts årbØger.

Fernández de Enciso, M. (1519): Suma de geographia. Sevilla, Jacobo Cromberger (Extramuros facsimiles, 2009).

Fernández de Navarrete, M. (1986): Viajes de Colón. México, Porrúa.

Fernández de Oviedo, G. (1992): Historia general y natural de las Indias. J. Pérez de Tudela Bueso (ed.). Madrid, bae.

Friederici, G. (1960): Americanistisches Wörterbuch und Hilfswörterbuch für den Amerikanisten. Hamburg, Cram, de Gruyter \& Co.

Grynäus, S. (1534): New // welt, der landschaft= //ten vnnd Jnsulen, so // bis he her allen Altweltbeschrybern vnbekant/ // Jungst aber von..., Straßburg. Universitäts und Landesbibliothek Sachsen-Anhalt (en linea: <http://bibliothek.uni-halle.de/dbib/ digital/historische_drucke/vd16/> [consulta: 10 de octubre de 2016].

Hansen Skon(n)ing, H. (1641): Geographia Historica Orientalis. Det er Atskillige Østerske Landis oc Øers / met deß Folcis Beskriffvelse: Nemlig / Tyrckers / Jøders / Grækers / Egypters / Indianers / Persianers / oc andre flere Landskabers underlige Sæder / Tro / Religion / Lower oc selsom Lands Maneer. Århus.

- (1660-80): "Páttur af Colombo um hans landa uppleitan og ókunnar siglingar". En Jónsson, M.: Ein ágæt, nytsöm, fróðleg, lystileg, skemmtirík og artug bók... Reykjavík (Biblioteca Handritasafn Landsbókasafns Íslands, ms. JS 43 4to), págs. 2r-6r.

Harisse, H. (1894): Lettre de Christophe Colomb annonçat aux rois catholiques la découverte du nouveau monde. Bibliographie de la version latine. Paris, $\mathrm{H}$. Walter.

Henriquez Ureña, P. (1938): Para la historia de los indigenismos. Buenos Aires, Instituto de Filología.

Henschel, C. (2005): Italienische und französische Reiseberichte des 16. Jahrhunderts und ihre Übersetzungen. Über ein vernachlässigtes Kapitel der europäischen Übersetztungsgeschichte. Darmstadt, Wissenschaftliche Buchgeschellschaft.

Hårbøl, K., Schack, J. y Spang-Hanssen, H. (1997): Fremmedordbog. København, Munkgaards.

Horstbøll, H. (1999): Menigmands medie. Det folkelige bogtryk i Danmark 1500-1840. København, Det Kongelige Bibliotek, Museum Tusculanums Forlag. íao = Örn og Örlygur (1990): Íslenska alfræðiorðabókin. Reykjavik, Örn og Örlygur.

Jónsson, M. (ed.) (1660-[80]): Ein ágæt, nytsöm, fróðleg, lystileg, skemmtirík og artug bók... Samantekin af virðulegum höfðingsmanni Magnúsi Jónssyni að Vigur. Reykjavík (Biblioteca Handritasafn Landsbókasafns Íslands, ms. JS 43 4to).

Kluge, F. (1999): Etymologisches Wörterbuch der deutschen Sprache. Berlin-New York, W. de Gruyter.

Kólumbus, K. (1992): Leiðarbækur Kólumbusar. S. Hjartarson (ed.). Reykjavík, Uglan. König, K. (1939): Überseeische Wörter im französischen (16.-18. Jahrhundert). Halle, Max Niemeyer. 
Las Casas, B. de (1951): Historia de las Indias. A. Millares Carlo (ed.). México-Buenos Aires, Fondo de Cultura Económica.

Lenz, R. (1904): Diccionario etimológico de las voces chilenas derivadas de lenguas indígenas americanas. Santiago de Chile, Universidad de Chile (en línea: <http://www. memoriachilena.cl/602/w3-article-9895.html> [consulta: 10 de octubre de 2016]).

libretto $=$ Libretto de tutta la Nauigatione de Re de Spagna de le isole et terreni nouamente trouati (1504). Venice (facsímil con introducción de L.C. Wroth. Paris, Librairie Ancienne Honoré Champion, 1930).

Mártir de Angleria, P. (1516): De orbe novo decades. Alcalá de Henares (en línea: $<$ http://fondosdigitales.us.es/fondos/libros/3629/4/de-orbe-novo-decades-curadiligentia-antonii-nebrissensis/> [consulta: 10 de octubre de 2016]).

- (1989): Décadas del Nuevo Mundo. R. Alba (ed.). Madrid, Polifemo.

Montalboddo, F. (1507): Paesi nouamente retrouate, Libro quarto. Vicenza, Henrico Vicentino (en linea: <https://bdigital.sib.uc.pt/bg1/> [consulta: 10 de octubre de 2016]).

Morales Padrón, F. (1990): Primeras cartas sobre América (1493-1503). Sevilla, Universidad de Sevilla.

Moromisato, L. (2009): "Procesos semántico-culturales de los vocablos caribe y caníbal en Las Casas". En Dakin, K. et al. (eds.): Visiones del encuentro de dos mundos en América. México-Los Ángeles, unam-University of California, págs. 79-92.

Nielsen, N.Å. (1995): Dansk Etymologisk Ordbog. Ordenes Historie. København, Gyldendal.

Nocentini, A. (2010): l'Etimologico. Vocabolario della lingua italiana. Milano, Le Monnier.

ntlle = Real Academia Española: Nuevo tesoro lexicográfico de la lengua española (ntlle) (en línea: <www.rae.es> [consulta: 10 de octubre de 2016]).

oed = Oxford (1989): Oxford English Dictionary. Oxford, ocp.

ods =Danske sprog- og literaturselskab, det (1975): Ordbog over det danske sprog. København, Gyldendal.

Ólafsson, J.G. (1956): «Magnús Jónsson í Vigur». Skírnir, cxxx, Reykjavík, Hið íslenska bókmenntafélag, págs. 107-125.

Palmer, P.M. (1939): Neuweltwörter im Deutschen. Heidelberg, Carl Winter's Universitätsbuchhandlung.

Pané, Fray R. (2004): Relación acerca de las antigüedades de los indios. J.J. Arrom (ed.). México-Buenos Aires, Siglo XXI.

Parodi, C. (2009): "La semántica cultural: un modelo de contacto lingüístico y Las Casas». En Dakin, K. et al. (eds.): Visiones del encuentro de dos mundos en América. México-Los Ángeles, unam-University of California, págs. 19-45.

Perissinotto, G. (1987): "Las primeras documentaciones de 'caribe'/caníbal' en las lenguas occidentales". Actas del i Congreso Internacional sobre español de América. San Juan, págs. 289-304.

Politiken (2000a): Nudansk med etymologi. København, Politikens forlag.

- (2000b): Etymologisk ordbog. Danske ords historie. København, Politikens forlag. 
roh = Ritmálssafn Orđabókar Háskólans [Instituto Lexicográfico de la Universidad de Islandia] (en línea: <http://lexis.hi.is/cgi-bin/ritmal/leitord.cgi?adg=innsl> [consulta: 10 de octubre de 2016]).

Sanz, C. (ed.) (1958): La unidad geográfica del descubrimiento de América. La carta de Colón anunciando la llegada a las Indias y a la Provincia de Catayo (China). (Descubrimiento de América). Madrid, Gráficas Yagües [facsimil 17 eds. conocidas].

Sadji, U. (1983): Newe unbekanthe landte und ein newe weldte in kurtz verganger zeythe erfunden, Buch iii-vi (Entdeckungsreisen nach Indien und Amerika. Der Druck der deutschen Übersetzung von 1508). Göppingen, Kümmerle.

Sejr, E. (1942): "Skonning, Hans Hansen». Dansk Biografisk Leksikon, 13, págs. 449450.

Serna, M. (ed.) (2005): Crónicas de Indias. Madrid, Cátedra.

Sixel, F.W. (1966): «Die deutsche Vorstellung vom Indianer in der ersten Hälfte des 16. Jahrhunderts». Annali del Pontifico Museo Misionario Etnologico, 30, págs. 9-230.

Segilinn, 17, 1930, pág. 152.

Taylor, D. (1958): “Carib, Caliban, Cannibal». International Journal of American Linguistics, 24.2, págs. 156-157.

tlfi = Gallimard (1992): Trésor de la langue française. París, cnrs (en línea: <http:// atilf.atilf.fr/> [consulta: 10 de octubre de 2016]).

Trumbull, J.H. (1875): “Cannibal». Notes and Queries, 5th S., iv, págs. 171-172.

Varela, C. y Gil, J. (1992): Textos y documentos completos de Cristóbal Colón. Madrid, Alianza.

Wroth, L.C. (ed.) (1930): Libretto de tutta la nauigatione de re de Spagna de le isole et terreni nouamente trouati. París, Libraire Ancienne Honoré Champion [facsímil].

Zingarelli, N. di (ed.) (2002): Lo zingarelli. Vocabolario della lingua italiana. Bologna, Zanichelli. 